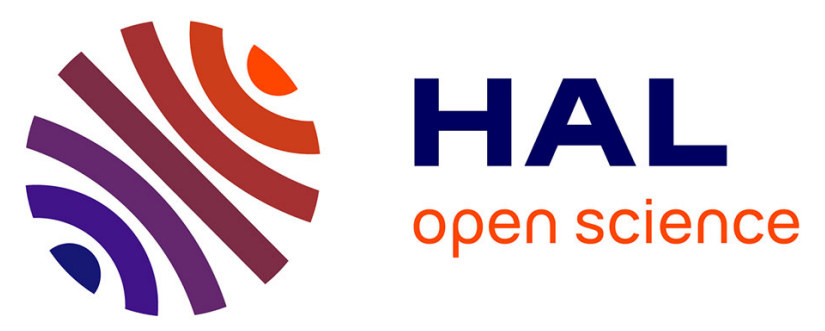

\title{
Influence of experimental parameters on physical properties of porous silicon and oxidized porous silicon layers
}

Joël Charrier, Vincent Alaiwan, Parastesh Pirasteh, Adel Najar, Michel Gadonna

\section{To cite this version:}

Joël Charrier, Vincent Alaiwan, Parastesh Pirasteh, Adel Najar, Michel Gadonna. Influence of experimental parameters on physical properties of porous silicon and oxidized porous silicon layers. Applied Surface Science, 2007, 253 (21), pp.8632-8636. 10.1016/j.apsusc.2007.04.056 . hal-00264785

\section{HAL Id: hal-00264785 https://hal.science/hal-00264785}

Submitted on 9 Nov 2021

HAL is a multi-disciplinary open access archive for the deposit and dissemination of scientific research documents, whether they are published or not. The documents may come from teaching and research institutions in France or abroad, or from public or private research centers.
L'archive ouverte pluridisciplinaire HAL, est destinée au dépôt et à la diffusion de documents scientifiques de niveau recherche, publiés ou non, émanant des établissements d'enseignement et de recherche français ou étrangers, des laboratoires publics ou privés.

\section{(c)(1)}

Distributed under a Creative Commons Attribution| 4.0 International License 


\title{
Influence of experimental parameters on physical properties of porous silicon and oxidized porous silicon layers
}

\author{
J. Charrier ${ }^{\mathrm{a}, *}$, V. Alaiwan ${ }^{\mathrm{a}}$, P. Pirasteh ${ }^{\mathrm{a}}$, A. Najar ${ }^{\mathrm{a}}$, M. Gadonna ${ }^{\mathrm{b}}$ \\ ${ }^{a}$ Laboratoire d'Optronique CNRS-UMR FOTON 6082, Université de Rennes 1, ENSSAT Tecnhopole Anticipa, 6 rue de Kérampont, \\ BP 447, 22305 Lannion, Cedex, France \\ ${ }^{\mathrm{b}}$ Centre Commun Lannionais d'Optique - CNRS-UMR FOTON 6082, Université de Rennes 1, ENSSAT Tecnhopole Anticipa, \\ 6 rue de Kérampont, BP 447, 22305 Lannion, Cedex, France
}

\begin{abstract}
This paper reports physical properties of porous silicon and oxidized porous silicon, manufactured by anodisation from heavily p-type doped silicon wafers as a function of experimental parameters. The growth rate and refractive index of the layers were studied at different applied current densities and glycerol concentrations in electrolyte. When the current density varied from 5 to $100 \mathrm{~mA} / \mathrm{cm}^{2}$, the refractive index was between 1.2 and 2.4 which corresponded to a porosity range from 42 to $85 \%$. After oxidation, the porosity decreased and was between 2 and $45 \%$ for a refractive index range from 1.22 to 1.46 . The thermal processing also induced an increase in thickness which was dependent on the initial porosity. This increase in thickness was more important for the lowest porosities. Lastly, the roughness of the porous layer/silicon substrate interface was studied at different applied current densities and glycerol concentrations in solution. Roughness decreased when the current density or glycerol concentration increased. Moreover, roughness was also reduced by thermal oxidation.
\end{abstract}

Keywords: Porous silicon; Thermal oxidation; Composition of electrolyte; Growth rate; Porosity; Refractive index; Roughness

\section{Introduction}

Porous silicon (PS) is a widely studied material to manufacture optical devices due to the easy modulation of its refractive index [1]. It can be used as a base material for passive or active optical devices such as Bragg reflectors [2,3], planar and buried waveguides [4-7], micro-cavities [8-10]. These optical multilayer-structures require that both the thickness and refractive index are well controlled. Moreover, to improve the properties of these photonic devices the roughness between porous layers should be reduced $[9,11]$.

Most of these structures are produced from PS layers. However, for some applications, the PS multilayers are oxidized to decrease absorption losses in order to obtain oxidized porous silicon (OPS) [12,13]. Many authors report quantitative measurements on porosity, growth rate and roughness notably for the case of PS layers [14-17].

\footnotetext{
* Corresponding author. Tel.: +33 296469114; fax: +33 296469076

E-mail address: joel.charrier@univ-rennes1.fr (J. Charrier).
}

In this paper, we report quantitative measurements for refractive index and growth rate obtained on PS and OPS single-layers as a function of applied current density and electrolyte composition. The thermal oxidation of porous layers induced an increase in thickness that was studied as a function of the initial porosity. The roughness of the porous layer/silicon substrate interface was also measured according to these experimental parameters.

\section{Experimental conditions}

Porous silicon layers were obtained by electrochemistry in the dark from heavily p-type doped $\left(\begin{array}{llll}1 & 0 & 0\end{array}\right)$-oriented silicon wafers $(5 \mathrm{~m} \Omega \mathrm{cm})$. The electrolyte was mechanically shaken. The physical parameters of samples (refractive index, growth rate, roughness) were studied as a function of the electrolyte composition. Four different electrolytes were used: (i) solution $\mathrm{S}_{1}$ composed of $\mathrm{HF}(50 \%): \mathrm{H}_{2} \mathrm{O}$ :ethanol (2:1:2) (ii) solution $\mathrm{S}_{2}$ composed of $\mathrm{HF}(50 \%): \mathrm{H}_{2} \mathrm{O}$ :ethanol:glycerol (2:1:1.5:0.5), (iii) solution $\mathrm{S}_{3}$ composed of $\mathrm{HF}(50 \%): \mathrm{H}_{2} \mathrm{O}$ :ethanol:glycerol 
Table 1

Composition of electrolytes as a function of the glycerol concentration (volumetric concentration)

\begin{tabular}{lllll}
\hline Name of solution & S1 & S2 & S3 & S4 \\
Concentration of glycerol (\%) & 0 & 10 & 20 & 40
\end{tabular}

The glycerol concentration represents the quantity of ethanol which was replaced by glycerol.

(2:1:1:1) and (iv) solution $\mathrm{S}_{4}$ composed of $\mathrm{HF}(50 \%): \mathrm{H}_{2} \mathrm{O}: \mathrm{gly}-$ cerol $(2: 1: 2)$. In order to measure the effect of the electrolyte composition on the roughness and refractive index, the viscosity of solution was varied by using glycerol to replace part of the ethanol whereas the HF concentration was kept constant for the four solutions. So, the solutions were characterized by their glycerol concentration (Table 1). Mono-layers of different porosities were formed by changing the value of the applied anodisation current $(J=15,30,50,70$, 80 and $100 \mathrm{~mA} / \mathrm{cm}^{2}$ ). The thickness of the layers was controlled by anodisation time. This was verified by optical microscopy.

Some of the as-prepared samples were oxidized in order to obtain porous silica [18]. Oxidation consisted of a two-step process. At first, the samples were pre-oxidized at $300{ }^{\circ} \mathrm{C}$ for one hour followed by an oxidation step at $900{ }^{\circ} \mathrm{C}$ in wet $\mathrm{O}_{2}$ for $1 \mathrm{~h}$.

The reflectance spectra of the porous materials (as-prepared and after oxidation) were studied by a LAMBDA 900 PerkinElmer beam spectrometer equipped with a specular reflectance module with a $6^{\circ}$ fixed angle. These measurements enabled the optical thickness to be determined by evaluating the beat of the interference fringes on the basis of the effective medium theory (Bruggeman model) [19,20]. Moreover, the roughness of PS/bulk silicon interface or OPS/bulk silicon interface was analyzed by AFM in tapping mode after dissolution of the porous layer. The PS layer was removed in an aqueous $\mathrm{NAOH}$ solution and that of the OPS in an aqueous diluted HF solution.

\section{Experimental results and discussion}

Because of multiple reflections inside the optical multilayerstructure, the quality of the interfaces is a crucial parameter. The interface roughness can be reduced by changing the electrolyte viscosity substituting a part of the alcohol by glycerol in the electrolyte or by using lower formation temperature $[9,11]$. That is why four solutions $S_{i}(i=1,2,3$ and 4) were used where the glycerol concentration was varied by replacing a part of the ethanol with glycerol.

The PS layers formed with the solution $S_{4}$ were not homogeneous and even could be removed from the silicon substrate notably for the highest current density values. This is why the use of $S_{4}$ is limited.

Fig. 1 shows the evolution of the growth rate $(v)$ as a function of the current densities for different concentrations. For all the solutions, the growth rate increases with current density. Moreover, the addition of glycerol in solution increases the growth rate for the same current density.

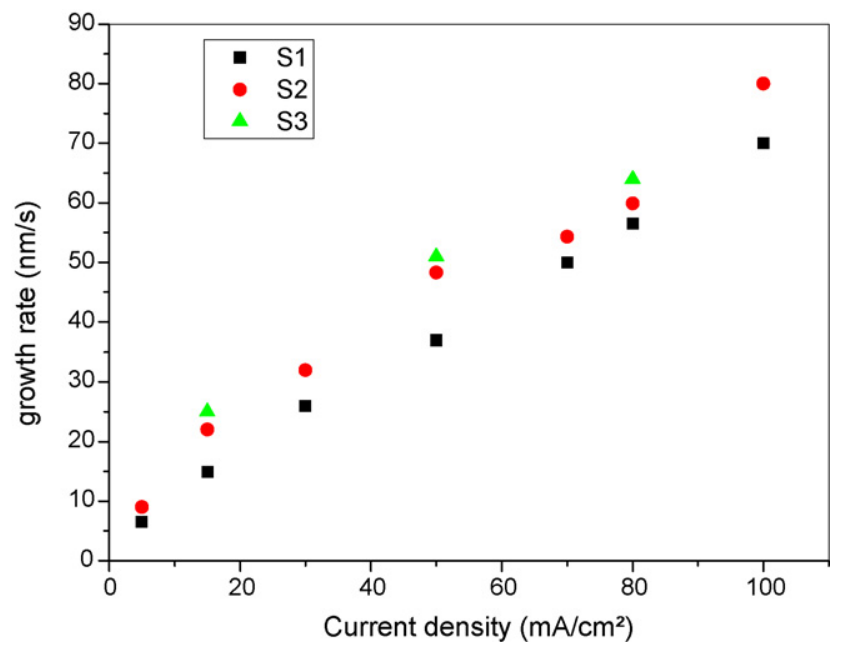

Fig. 1. Evolution of porous silicon growth rate as a function of the current density for three glycerol concentrations ( $\mathrm{S} 1 \mathrm{C}=0 \%, \mathrm{~S} 2 \mathrm{C}=10 \%$ and $\mathrm{S} 3$ $\mathrm{C}=20 \%$ ).

The growth rate $(v)$ is dependent on the current density $(J)$ according to the following formula:

$v=\frac{J}{p(J) n_{v}(J) e N_{\mathrm{Si}}}$

where $p(J)$ is the porosity, $n_{v}(J)$ the number of exchanged charge carriers per dissolved silicon atom (valence), $e$ the elementary charge and $N_{\mathrm{Si}}$ the atomic density of Silicon [14]. This relation links growth rate and current density. The experimental results confirm that the growth rate increases with current density.

Lastly, the increase in growth rate with glycerol concentration may be explained by the increase in viscosity of the electrolytic solution.

From the reflectance spectra, the refractive indices of the PS layers were deduced. These values are shown in Fig. 2 as a function of the current density for the three glycerol

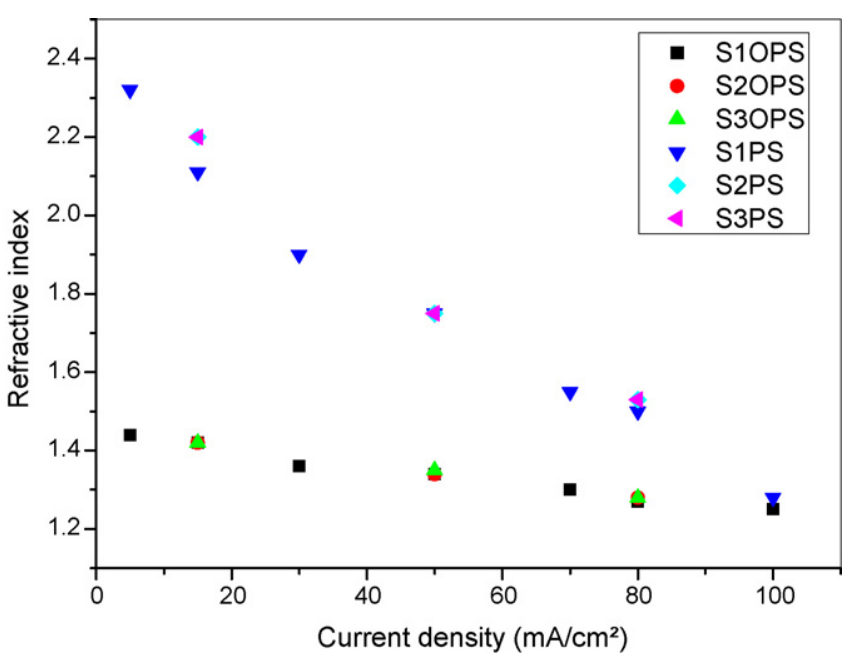

Fig. 2. Evolution of porous silicon and oxidized porous silicon refractive index as a function of the current density for three glycerol concentrations ( $\mathrm{S} 1$ $\mathrm{C}=0 \%, \mathrm{~S} 2 \mathrm{C}=10 \%$ and $\mathrm{S} 3 \mathrm{C}=20 \%$ ). 
concentrations. We can notice that for the three solutions, the index is approximately the same $(\Delta n= \pm 0.01)$ for each applied current density value. The refractive index does not depend on the glycerol concentration. The refractive index decreases when the current density increases and the values of PS refractive indices are between 1.2 and 2.4 in the range of applied current densities.

Of course, after oxidation, the refractive indices were lower than those of the PS layers. The variation of refractive index of OPS layers as a function of the current density for the three electrolytes is also shown in Fig. 2. The same trend was observed: the refractive index decreases when the current density increases. For the lowest applied current density $\left(J=5 \mathrm{~mA} / \mathrm{cm}^{2}\right)$, the refractive index was nearly equal to that of silica. The refractive index varied between 1.25 and 1.46 . To achieve nanostructured optical devices, the refractive index range before and after oxidation must be known. In the case of our study, the refractive index change is equal to 1.04 (from 2.32 to 1.28 ) before oxidation and equal to 0.19 (from 1.44 to 1.25) after oxidation (Fig. 2).

The values of porosity of the layers were estimated from their refractive indices by using the Bruggeman model. These measurements were verified by weight measurements at certain current densities $\left(50\right.$ and $80 \mathrm{~mA} / \mathrm{cm}^{2}$ ). Fig. 3 represents the evolution of PS porosity as a function of applied current density. The porosity increases when the current density increases. Since the refractive index at the same current density is nearly the same for all the used electrolytes, the porosity is also approximately the same. The porosity varies between 42 and $85 \%$ for current densities between 5 and $100 \mathrm{~mA} / \mathrm{cm}^{2}$.

In the case of OPS, the layers are assumed to be completely oxidized [18]. The evolution of the calculated porosity for OPS layers is also shown in Fig. 3 as a function of current density. After oxidation, the porosity decreases due to the transformation of silicon crystallite into silica which is accompanied by a volume expansion [21]. The refractive index values are always inferior to that of silica (Fig. 4) and this demonstrates that the

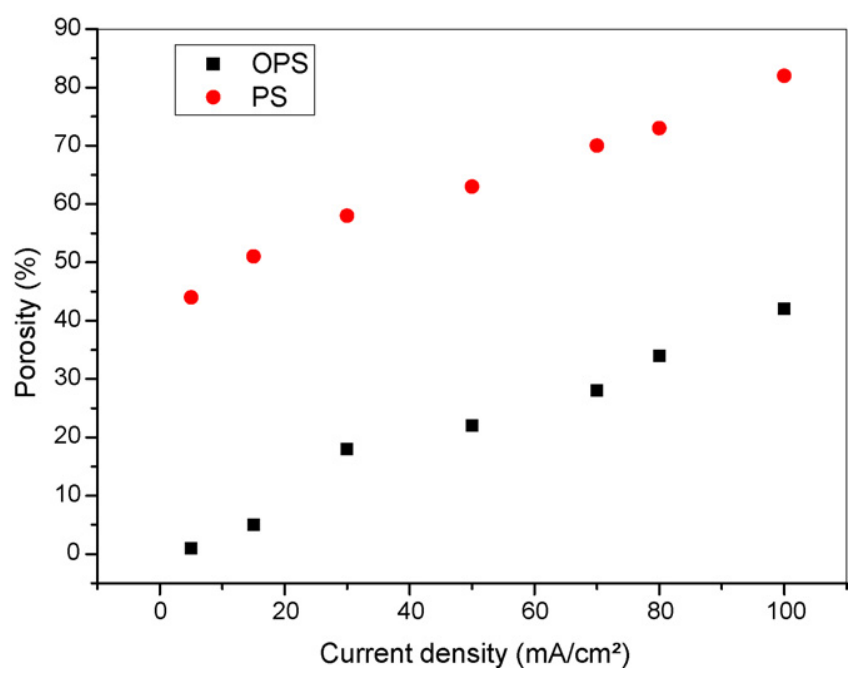

Fig. 3. Evolution of porous silicon and oxidized porous silicon porosity as a function of the current density.

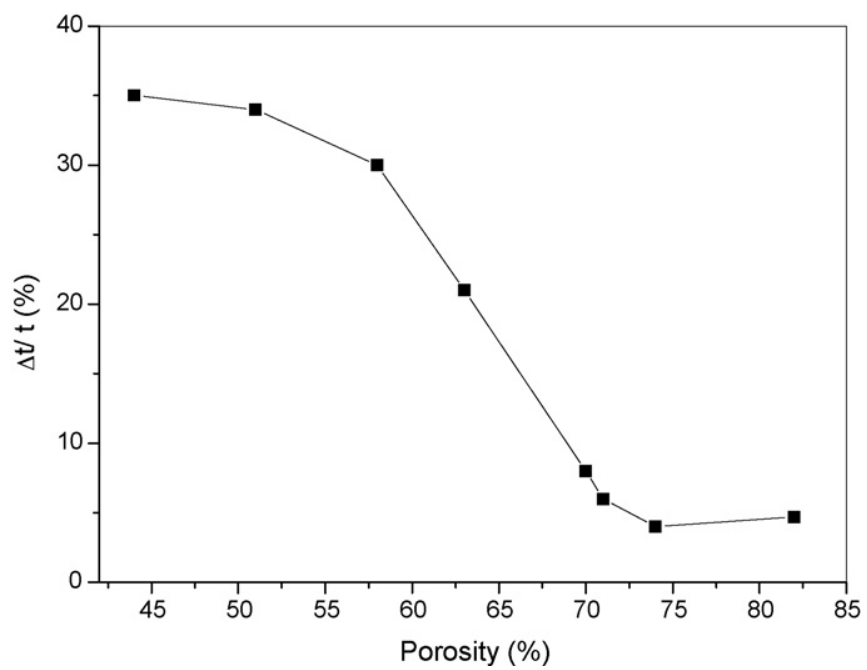

Fig. 4. Evolution of the relative variation in thickness before and after oxidation as a function of the porous silicon porosity.

oxidized layers always remain porous. For this range of current densities, the residual porosity is between 2 and $45 \%$. These porosity values of OPS layers obtained by the Bruggeman model are compared with those calculated by the following expression from [21]:

$p_{\mathrm{OPS}}=1-2.27 \frac{t_{\mathrm{PS}}}{t_{\mathrm{OPS}}}\left(1-p_{\mathrm{PS}}\right)$

with $t_{\mathrm{PS}}$ and $t_{\mathrm{OPS}}$ the experimental values of PS layer thickness and OPS layer thickness and $p$ PS layer porosity.

The calculated values of porosity are reported in Table 2 . The results show that a difference exits between the values of the calculated porosity and those deduced from the Bruggeman model.

During oxidation, the thickness of the layers increases. We have observed a relative variation in thickness $(\Delta t / t)$ before and after oxidation given by $\Delta t / t=\left(t_{\mathrm{OPS}}-t_{\mathrm{PS}}\right) / t_{\mathrm{PS}}$ as a function of

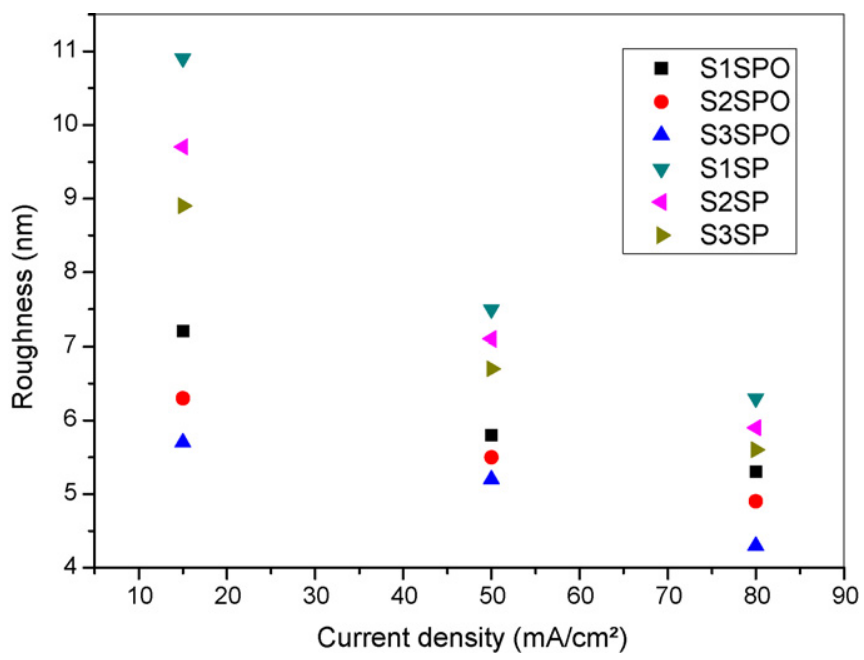

Fig. 5. Evolution of porous silicon and oxidized porous silicon roughness as a function of current density for three glycerol concentrations ( $\mathrm{S} 1 \mathrm{C}=0 \%, \mathrm{~S} 2$ $\mathrm{C}=10 \%$ and $\mathrm{S} 3 \mathrm{C}=20 \%$ ). The thickness of the samples is about $2 \mu \mathrm{m}$. 
Table 2

Porosity of the oxidized porous silicon layers as a function of the current density calculated by Bruggeman model and deduced from thickness measurements

Porosity deduced from Bruggeman model $(\%)$

Porosity deduced from thickness measurements $(\%)$

\begin{tabular}{rrrrrrr}
5 & 15 & 30 & 50 & 70 & 80 & 100 \\
1 & 5 & 18 & 22 & 28 & 34 & 42 \\
6 & 17 & 27 & 31 & 37 & 41 & 61 \\
\hline
\end{tabular}
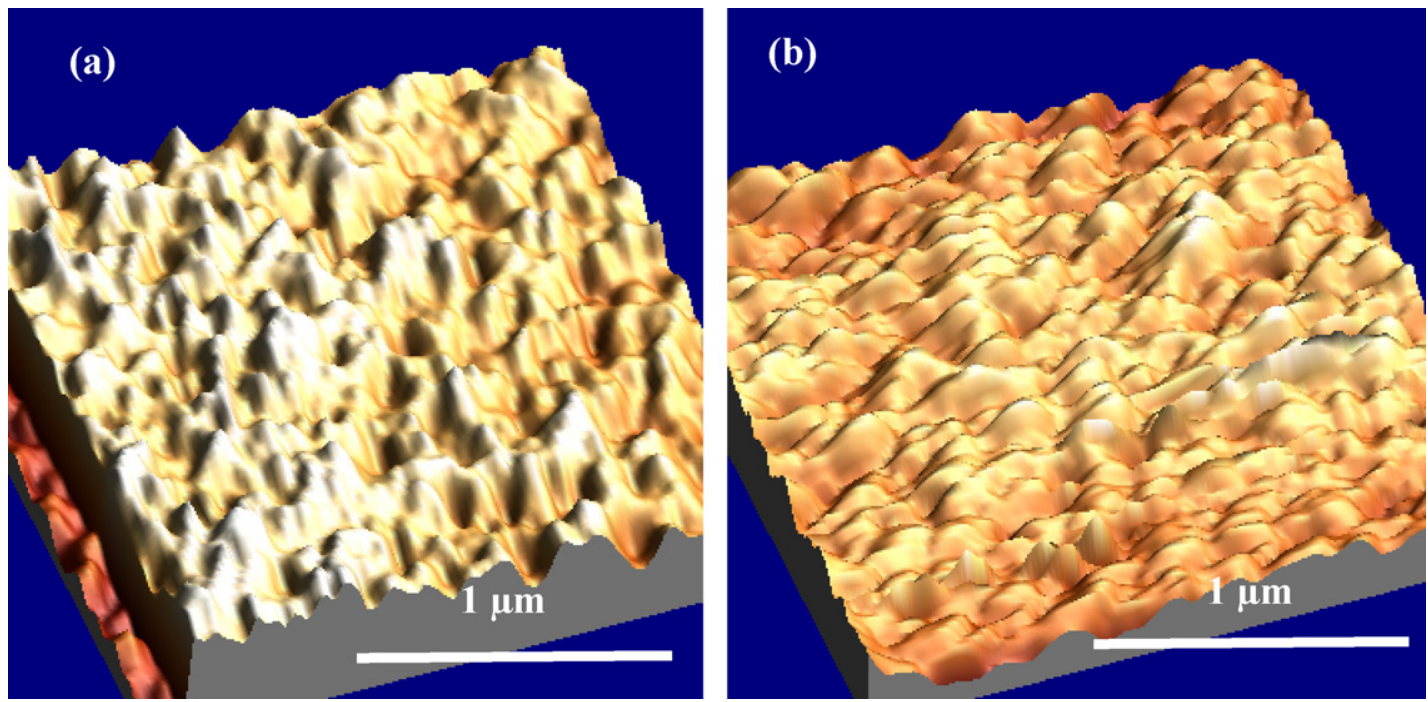

Fig. 6. 3D-profile of (a) porous silicon/silicon substrate interface obtained by AFM; (b) oxidized porous silicon/silicon substrate interface obtained by AFM

initial porosity of the PS layer (Fig. 4). The values of the relative variation in thickness were obtained by taking the average of the thicknesses of several samples formed at the same applied current density but with different anodisation times. This increase in layer thickness was always observed after oxidation and it was greater for the lower porosities. It decreased when the initial porosity increased and reached an asymptotic value for the highest porosities. This variation was very important for porosites between 50 and $70 \%$ before oxidation. We have noticed that the increase in thickness was less important for the highest porosities. This phenomenon could be explained by the transformation of silicon into silica which mainly occurred inside the pores with the highest porosities whereas for the lowest porosities it occurred according to the thickness of the layer. This increase in thickness must be taken into account in the optical thickness after oxidation for OPS multilayer optical devices.

The evolution of roughness that represents the root mean square (rms) deviation of the planarity at interfaces $(\sigma)$, as a function of layer thickness for different current densities is known [22]: the curve is initially linear before becoming saturated. The evolution of PS layer roughness as a function of current density for the three solutions is shown in Fig. 5. Each measurement of roughness was performed on the substrate from which the $2-\mu \mathrm{m}$ thick PS layer had been removed to enable values to be compared. For a fixed solution, the roughness induced by a higher applied current density is always lower than when a lower current density is applied. The same trend was observed for all the used solutions. Moreover, at the same applied current density, roughness also decreased when the glycerol concentration in solution increased.

We think that the increase in current density or viscosity of the electrolytic solution permits smoother PS layers to be obtained. In fact, when the electropolishing current is applied, there is no roughness. Under this condition, it is generally admitted that a viscous state exists near the etched surface in which the diffusion of the reactive chemical species is difficult [23]. So, in this regime the electrochemical reaction is favored on the peaks of the surface and has then a smoothening role.

After oxidation, the values of roughness are always lower for all the samples (Fig. 5). Fig. 6 shows the 3D-profiles of PS/Sisubstrate interface (Fig. 6a) and that of OPS/Si-substrate obtained by AFM (Fig. 6b). These measurements were performed on the bulk interface after removing a $2 \mu \mathrm{m}$ porous layer obtained by applying a $15 \mathrm{~mA} / \mathrm{cm}^{2}$ current density with solution $S_{1}$. We can notice the modification of relief and the decrease in roughness after oxidation. This decrease in roughness after oxidation was also observed by Pap et al. [17] and the value of roughness depended on oxidation temperature. Indeed, the oxidation has a smoothening effect.

\section{Conclusion}

We have studied the influence of experimental parameters (applied current density, composition of electrolyte) on physical characteristics of porous silicon and oxidized porous silicon layers. The results show that the growth rate increases with both these experimental parameters. The roughness of the porous layer/silicon substrate interface decreases when the 
current density or viscosity of solution increases. We have also studied the refractive index of the porous layers before and after oxidation according to a range of applied current densities. These studies permit the refractive index and layer thickness for a fixed current density to be obtained.

All these results enable us to control the optical thickness so that multilayer optical devices such as waveguides, Bragg reflectors or micro-cavities will be able to be manufactured.

\section{References}

[1] C. Pickering, V. Beale, D. Robbins, P. Pearson, R. Greef, J. Phys. C, Solid State Phys. 17 (1984) 1790.

[2] L. Pavesi, P. Dubos, Semicon. Sci. Technol. 12 (1997) 570.

[3] M.G. Berger, R. Arens-Fisher, M. Thönissen, M. Krüger, S. Billat, H. Lüth, S. Hillbrich, W. Theiss, P. Grosse, Thin Solid Film 297 (1997) 237.

[4] A. Loni, L.T. Canham, M.G. Berger, R. Arens-Fisher, H. Munder, H. Luth, H.F. Arrand, T.M. Benson, Thin Solid Films 276 (1996) 143.

[5] J. Charrier, C. Lupi, L. Haji, C. Boisrobert, Mat. Sci. Semicond. Process. 3 (2000) 357.

[6] M. Balucani, V. Bondarenko, E. Fazio, G. Lamedica, K. Ricciardelli, E. Viarengo, A. Ferrari, H.F. Bulthuis, F.M. van der Vliet, J.E. Broquin, G. Vitrant, 12th Annual Meeting, LEOS '99, vol. 2, IEEE, San Francisco, CA, USA, 1999, (1999), p. 643.
[7] M. Balucani, V. Bondarenko, A. Klusko, A. Ferrari, Opt. Mater. 27 (2005) 776.

[8] L. Pavesi, C. Mazzoleni, A. Tredicuccia, V. Pellegrini, Appl. Phys. Lett. 67 (1995) 3280.

[9] S. Setzu, P. Ferrand, R. Romestain, Mater. Sci. Eng. B69-B70 (2000) 34.

[10] V. Mulloni, L. Pavesi, Appl. Phys. Lett. 76 (2000) 2523.

[11] S. Setzu, G. Lerondel, R. Romestain, J. Appl. Phys. 84 (1998) 3129.

[12] M. Gaillet, M. Guendouz, M. Ben Salah, B. Le Jeune, G. Le Brun, Thin Solid Film 410 (2004) 455.

[13] P. Pirasteh, J. Charrier, Y. Dumeige, S. Haesaert, P. Joubert, J. Appl. Phys. 101 (2007) 083110.

[14] L.T. Canham, «Properties of Porous Silicon», Eds. INSPEC (1997).

[15] K. Kordás, J. Remes, S. Beke, T. Hu, S. Leppävuori, Appl. Surf. Sci. 178 (2001) 190.

[16] A.E. Pap, K. Kordás, A. Uusimäki, J. Vähäkangas, S. Leppävuori, L. Pilon, S. Szatmári, Opt. Mater. 28 (2006) 506.

[17] A.E. Pap, K. Kordás, TóthF G., J. Levoska, A. Uusimäki, J. Vähäkangas, S. Leppävuori, T.F. George, Appl. Phys. Lett. 86 (2005) 041501.

[18] P. Pirasteh, J. Charrier, A. Soltani, S. Haesaert, L. Haji, C. Godon, N. Errien, Appl. Surf. Sci. 253 (2006) 1999.

[19] D.E. Aspnes, Thin Solid Films 89 (1982) 249.

[20] W. Theiss, Surf. Sci. Rep. 29 (1997) 91.

[21] K. Barla, R. Herino, G. Bomchil, J. Appl. Phys. 59 (1986) 439.

[22] G. Lerondel, R. Romestain, S. Barret, J. Appl. Phys. 81 (1997) 6171.

[23] D.R. Turner, J. Electrochem. Soc. 105 (1957) 402. 